\title{
Experimental Clarification of Flame Ejection in the Presence of Wind and its Application in Models - Development of a Model for Fire Propagation between Buildings in Urban Areas -
}

\author{
Naofumi Kodama ${ }^{1}$, Yoshihiko Hayashi ${ }^{2}$, Yoshifumi Ohmiya ${ }^{1}$ and Tatsuya Iwami ${ }^{3}$ \\ ${ }^{1}$ Tokyo University of Science \\ ${ }^{2}$ Building Research Institute \\ ${ }^{3}$ National Institute for Land and Infrastructure Management, Ministry of Land Infrastructure and \\ Transport
}

Keywords : Compartment Fire, Wind Conditions, Flame Ejected Through Opening, Fire in Urban Areas, Simulation Model for Fire Spread

\section{INTRODUCTION}

Building research institutes, and National Institute for Land and Infrastructure Management, have come to use physically based simulation models for fire propagation in urban areas [1] as a tool for estimating fireproof performance in urban areas. However, the need for higher accuracy models has pushed forward their development, while at the same time it is necessary to construct several sub-models. In the present research, we have constructed a fire pattern model through experiments elucidating the process of fire ejection through an opening in a compartment, which ranks as the most important type of sub-model. Furthermore, it has been validated by applying it to urban area fire propagation simulation models.

\section{EXPERIMENTAL OVERVIEW}

\subsection{Equipment used in the experiment}

Figure 1 shows an overview of the equipment used in the experiment. The fire compartment is a cube with inside dimensions of $0.8 \mathrm{~m}$, constructed from ceramic fiber boards ( $25 \mathrm{~mm}$ thick). The opening $(B \times H)$ is located in the center of the leeward-side wall which is perpendicular to the direction of the wind. The fire source is a gas burner, and the fire source area is $0.3 \mathrm{~m} \times 0.3 \mathrm{~m}$. The burner is set at the center of the compartment floor, and the upper surface is level to the surface of the floor. Propane gas is used as fuel. 


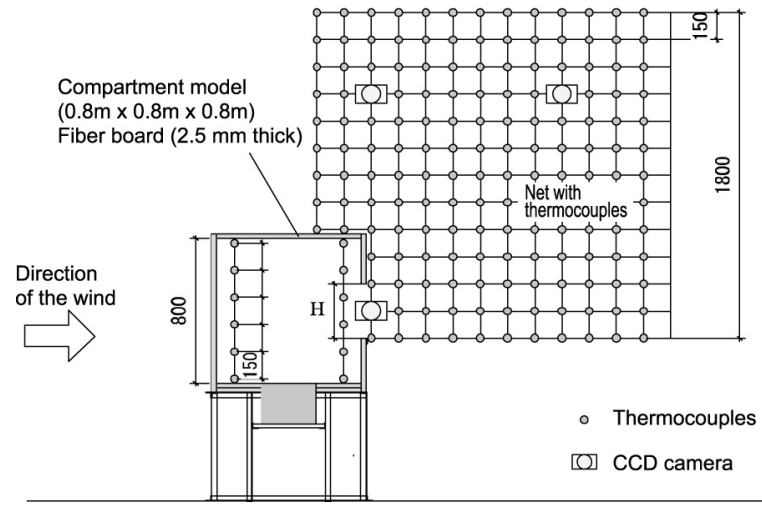

Figure 1 Experimental equipment and each measurement point (cross section plan, unit: $\mathrm{mm}$ )

\subsection{Experimental parameters}

Table 1 shows the parameters of the experiment. In this experiment, the breadth $B$ of the opening, the height $H$ of the opening, as well as the heat release rate are regarded as parameters.

Table 1 Experimental parameters

\begin{tabular}{|c|c|c|c|c|}
\hline $\begin{array}{c}\text { Wind velocity } \\
v(\mathrm{~m} / \mathrm{s})\end{array}$ & $\begin{array}{c}\text { Breadth of } \\
\text { opening } B(\mathrm{~m})\end{array}$ & $\begin{array}{c}\text { Height of } \\
\text { opening } H(\mathrm{~m})\end{array}$ & $\begin{array}{c}\text { Opening factor } \\
A H^{1 / 2}\left(\mathrm{~m}^{5 / 2}\right)\end{array}$ & $\begin{array}{c}\text { Heat release rate } \\
Q(\mathrm{~kW})\end{array}$ \\
\hline \multirow{5}{*}{$0,1,2,3,4$} & 0.2 & 0.3 & 0.0329 & 98.6 \\
\cline { 2 - 5 } & 0.3 & 0.2 & 0.0268 & 68.4 \\
\cline { 2 - 5 } & \multirow{2}{*}{0.2} & \multirow{2}{*}{0.2} & \multirow{2}{*}{0.0179} & 80.5 \\
\cline { 2 - 5 } & & & & 45.6 \\
\hline
\end{tabular}

\subsection{Measured variables}

In order to measure the temperature of the ejected flame and the fire plume, K-type thermocouples were installed at the center of the opening, such that the measurement plane is perpendicular to the opening. The measurement area is set as $1.5 \mathrm{~m}$ in the horizontal direction from the plane of the opening and $1.8 \mathrm{~m}$ in the vertical direction from the lower edge of the opening, and the thermocouples were installed on a steel lattice with $0.15 \mathrm{~m}$ interstice. Furthermore, the temperature inside the fire compartment was measured by installing thermocouples at $0.15-\mathrm{m}$ intervals in the vertical direction in the front left and the back right corner with respect to the opening. Moreover, a comparison of the temperature distribution was performed by recording the fire with a CCD camera installed laterally in the compartment. 


\section{EXPERIMENTAL RESULTS AND DISCUSSION}

\subsection{Shape of the flame ejected through the opening}

Figure 2 relates to the choice of the symbols, etc. used for processing the shape of the flame ejected through the opening in the compartment. The position of the tip of the flame was defined by using the values from the CCD camera.

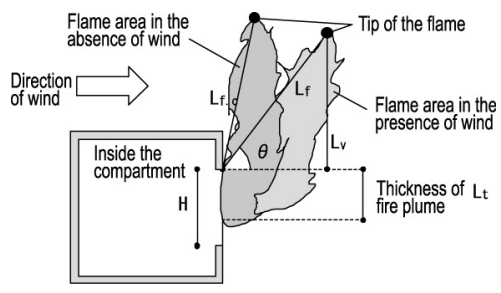

Figure 2 Conceptual diagram of flame condition (cross section)

\subsubsection{Length of the ejected flame}

The flame ejected from free space or from the compartment opening can be expressed together on the basis of formulae in which the dimensionless flame length and the dimensionless heat release rate are used as parameters. Therefore, with respect to the results of the present experiment regarding the flame length in the absence of wind, Figure 3 represents a plot of each parameter on the abscissa and the ordinate. Here, Equation 1 gives the value of the dimensionless heat release rate $Q$, whereby it takes into account the burning of the gas outside of the compartment, which has not been burned up. In other words, the amount of heat released by the ejected flame is the sum of the enthalpy of the ejected current and the calorific value of the unburned gas. The calorific value of the unburned gas is written inside curly brackets $\{$ in Equation 1, and the value is formed by subtracting the heat release rate of the combustion inside the compartment from the heat release rate of the fire source. Furthermore, the values of the mass flow rates $m_{\text {in }}$ and $m_{\text {out }}$ into and out of the compartment are inferred from calculation, ${ }^{1)}$ which takes into account the wind pressure.

$$
Q=c_{p} \dot{m}_{\text {out }}\left(T_{\text {in }}-T_{\infty}\right)+\left\{Q_{c}-\Delta H_{\text {air }} \dot{m}_{\text {in }}\right\}
$$

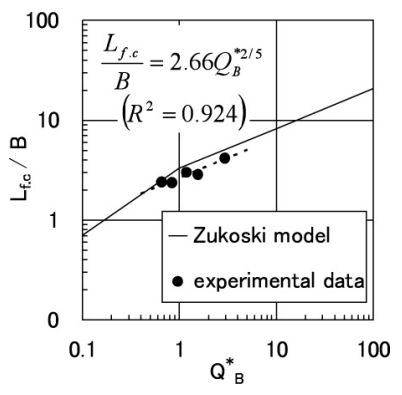

Figure 3 Length of fire plume 
In addition, the breadth of the opening was for the characteristic flame length. The experimental results revealed that the correlativity is higher when power multipliers are used in free space, and Equation 2 represents the regression expression. Furthermore, the dimensionless flame length formed by dividing the flame length in the presence of wind by the flame length in the absence of wind is plotted along the ordinate in Figure 4. Consequently, the value of the ordinate becomes roughly 1 , and it is considered that Equation 2 is also applicable in the case of the presence of wind.

$$
L_{f . c} / B=2.66 Q_{B}^{* 2 / 5}
$$

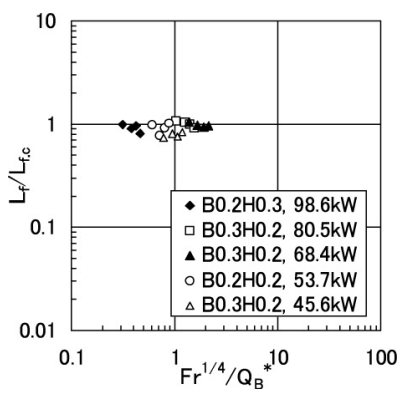

Figure 4 Flame lengths in the presence of wind

\subsubsection{Vertical flame length in the presence of wind}

By considering that there is a proportional relation between the climbing power of a flame, declined at an angle of $\theta$, and the inertial force $F_{r}$ of a horizontal wind, Equation 3 can be expressed in the following way.

$$
L_{v} / B \propto F r^{m} Q^{* n}
$$

Based on the above assumption, Figure 5 represents a plot of the relation between the vertical flame length and the pairing parameter as the results of the present experiment. Equation 4 gives the regression expression obtained through the experiment.

$$
L_{v} / B=2.52\left(\mathrm{Fr}^{1 / 4} / Q^{*}\right)^{-1 / 3}
$$

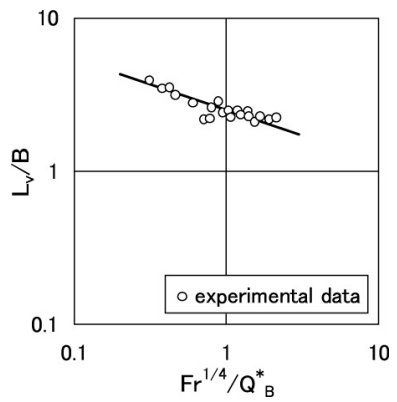

Figure 5 Vertical length of the flame 


\subsubsection{Flame declination angle}

The flame inclined angle is expressed as $L_{v} / L_{f}$ from Equations 2 and 4 . Consequently, the estimation model from the flame inclined angle is given as Equation 5.

$$
\left\{\begin{array}{cl}
\sin \theta=1 & \left(F^{1 / 4} Q_{B}^{* 1 / 5} \leq 0.94^{3}\right) \\
\sin \theta=0.94\left(F r^{1 / 4} Q_{B}^{* 1 / 5}\right)^{-1 / 3} & \left(F r^{1 / 4} Q_{B}^{* 1 / 5}>0.94^{3}\right)
\end{array}\right.
$$

\section{IMPROVEMENT AND VALIDATION OF THE URBAN AREA FIRE PROPAGATION SIMULATION MODEL}

\subsection{Improvement of the model}

In core models, the units are set as regions called compartments, and fire propagation in urban areas is regarded as the progression of fire within the compartments and the transferral of fire between compartments. Depending on the aspects of flame ejection, fire progression within the compartments is divided into 5 modes, as shown in Figure 6, and the progression is regarded as a succession of modes. We have applied the relation formulae for the shape of the ejected flame, obtained from the present experiment, as sub-models of heat sources outside the compartments to the existing core models. Equation 2 regarding the flame length was applied to mode 1, and the already established formulae were used for modes 2 and 3. In the same way, Equation 5 was applied with respect to the fire declination angle.

\begin{tabular}{|c|c|c|c|c|c|c|}
\hline & Ignitable area & mode 1 & mode 2 & mode 3 & mode 4 & \\
\hline $\begin{array}{l}\begin{array}{l}\text { Fire proof } \\
\text { structure }\end{array} \\
\text { s }\end{array}$ & 10 & U & & & $\square$ & $\begin{array}{l}\text { Fire progression } \\
\text { (fire plume behavior) }\end{array}$ \\
\hline $\begin{array}{l}\text { Fire retarding } \\
\text { structure }\end{array}$ & 圆 & 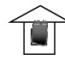 & 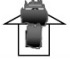 & & m & $\begin{array}{l}\text { Mode1: Opening } \\
\text { Mode2: Opening and roof }\end{array}$ \\
\hline $\begin{array}{l}\text { Wood and/or } \\
\text { fragile } \\
\text { structure }\end{array}$ & $\hat{a}$ & & & & . & $\begin{array}{l}\text { Mode3: Entire compartment } \\
\text { Mode4: After fire was extinguished }\end{array}$ \\
\hline
\end{tabular}

Figure 6 Scenario for fire progression

\subsection{Validation through an idealized lattice-shaped urban area}

\subsubsection{Computational parameters}

As shown in Figure 7, an idealized urban area was assumed, whereby the compartments are located on a lattice. Each side of the urban area constitutes 15 two-story buildings (each side of the building is $8 \mathrm{~m}$, and the storey height is $3 \mathrm{~m}$ ), which are $2 \mathrm{~m}$ apart, for a total of 225 buildings. The buildings are fire-resistant wooden structures, semi-fireproof structures or fireproof structures, and each of the 4 side walls has $1 \mathrm{~m} \times 1 \mathrm{~m}$ openings on the left and the right side on each floor, for a total of 4 openings per wall. 


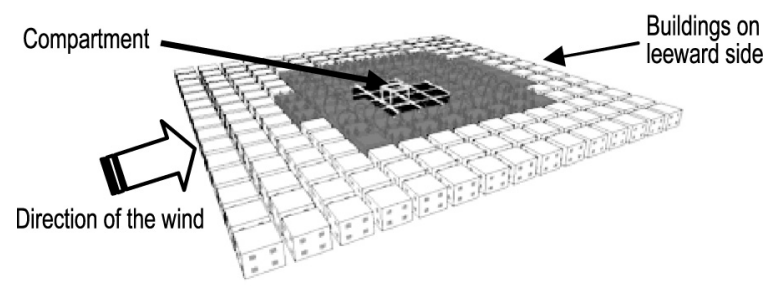

Figure 7 Virtual urban area

\subsubsection{Computational results}

Pre- and post-improvement simulations were performed by changing the wind speed parameter, and the results of comparing the fire propagation speeds are shown in Table 2. Furthermore, the fire propagation speeds (the differences in distance from the center/time of fire breakout) are taken between the building located in the middle of the picture, where the fire originated, and each building in an upwind, a downwind and a sideway direction. Since the results for the upwind and sideway directions are not very different, they are not discussed in the present paper.

The following tendencies were confirmed by the computational results:

(1) The fire propagation speed is higher for buildings with fragile constructions.

(2) Compared to the pre-improvement model, in the post-improvement model the fire propagation speed is low for wind speeds below $2 \mathrm{~m} / \mathrm{s}$, and increases for wind speeds above $4 \mathrm{~m} / \mathrm{s}$.

Regarding the combustion configuration with respect to (1), taking the fire propagation for each type of construction as shown in Figure 6, it is considered to be due to the fact that the thermal influence exerted on the vicinities of the fire compartment is different. Furthermore, as the wind speed increases, the flames ejected through the openings (model 1) become a stronger propagation factor, and the result is that the propagation speed increases for any type of construction. Regarding (2), since in the post-improvement model, as compared with the pre-improvement one, the declination angle of the flames ejected through the openings in the presence of low-speed wind is smaller, it is considered that the propagation speed is slowed down.

Table 2 Comparison of spreading speed

\begin{tabular}{|c|c|cc|cc|cc|cc|}
\hline \multirow{2}{*}{ Structure } & \multirow{2}{*}{ Wind } & \multicolumn{2}{|c|}{$0 \mathrm{~m} / \mathrm{s}$} & \multicolumn{2}{c|}{$2 \mathrm{~m} / \mathrm{s}$} & \multicolumn{2}{c|}{$4 \mathrm{~m} / \mathrm{s}$} & \multicolumn{2}{c|}{$6 \mathrm{~m} / \mathrm{s}$} \\
\cline { 3 - 10 } & & Before & After & Before & After & Before & After & Before & After \\
\hline Fire Retarding & leeward & 18.8 & 18.8 & 30.9 & 21.1 & 59.2 & 64.6 & 65.6 & 65.6 \\
Semi Fire Proof & leeward & 13.8 & 13.8 & 26.1 & 17.8 & 49.4 & 53.8 & 49.4 & 53.8 \\
Fire Proof & leeward & - & - & 19.9 & 1 & 45.7 & 49.4 & 49.4 & 53.8 \\
\hline
\end{tabular}




\section{SUMMARY}

In the present research, the experimental results were processed by using $Q^{*}$, which takes into account the unburned gas when considering the length of the ejected flames, and a new flame shape model which is applicable in the presence of wind was constructed. Furthermore, by integrating the above model into a flame propagation simulation model, the fire propagation speeds were compared by making use of an idealized urban area.

\section{SYMBOLS}

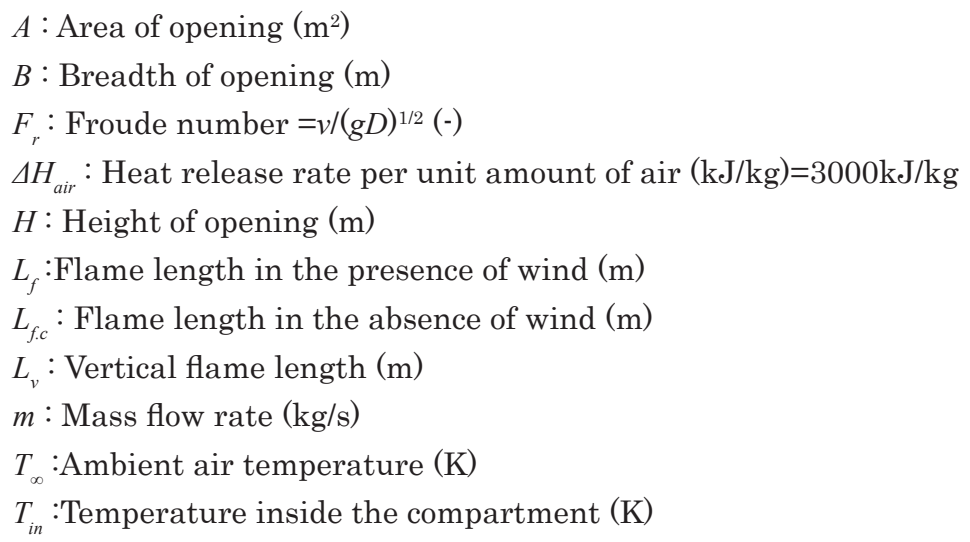

\section{REFERENCES}

1. Iwami T, Ohmiya Y., Hayashi Y., Naruse T., Takeya S., Kagiya K., Itoigawa E. KatoT., Shida K. Hokugo A. and Takahashi W., "Development of Evaluation Method of Urban Fire Risk", BRI research paper, Vol.145, 2006 (in Japanese)

2. Shizuo Y., "Study on Height of Fire", Bulletin of Japan Association for Fire Science and Engineering, vol3, No1, 1963 (in Japanese)

3. Tanaka T., "Introduction to Architectural Fire Safety Engineering", Building Center of Japan, pp.164, 1993 (in Japanese) 